\title{
Patient triggered ventilation using a flow triggered system
}

\author{
Michael F Hird, Anne Greenough
}

\begin{abstract}
The role of patient triggered ventilation (PTV) for the newborn was assessed using a new patient triggered ventilator, the Draeger Babylog 8000, which incorporates significant improvements in both ventilator performance and the triggering system. Thirty three infants, median gestational age 30 weeks and postnatal age 2.5 days, were entered into the study to compare blood gases obtained during conventional and patient triggered ventilation. Oxygenation did not improve with PTV in the group overall but increased significantly (median change 7\%) in infants greater than 28 weeks' gestation. Arterial carbon dioxide tension $\left(\mathrm{PaCO}_{2}\right)$ decreased during PTV in the majority of infants (median reduction $7 \%$ ), this was not related to the gestational or postnatal age, but was greatest in infants previously on a low conventional ventilation rate. Blood gases (both $\mathrm{PaO}_{2}$ and $\mathrm{PaCO}_{2}$ ) deteriorated in infants requiring the highest inspired oxygen concentration. We conclude that patient triggered ventilation is most useful in infants with mild respiratory distress.
\end{abstract}

Patient triggered ventilation (PTV) was reintroduced as a method of respiratory support for neonates in $1986 .{ }^{1}$ Since that time there have been a series of studies which have assessed both the possible short $^{1-3}$ and long term benefits of PTV. ${ }^{45}$ In the majority of infants oxygenation acutely improves on transfer from conventional ventilation to PTV $^{1-3}$ but PTV fails to provide a successful method of respiratory support in infants of less than 28 weeks' gestation 4 or if it is started in the first 24 hours of life. ${ }^{5}$ A predictor of failure of PTV was an asynchronous respiratory interaction, with inflation occurring either late in inspiration or even in expiration, as a result of a long trigger delay. ${ }^{5}$ All these studies have employed a modified conventional neonatal ventilator (model HV 2000, SLE) with a variety of triggering systems.

Recently, purpose built patient triggering ventilators have appeared. We have demonstrated that one such ventilator (Draeger Baby$\log 8000$ ) has a performance superior to the SLE, with a much shorter trigger delay: a median of 80-100 ms (Draeger) compared with a median of 200-250 ms (SLE). ${ }^{6}$ The Draeger Babylog 8000 also has the advantage of no inadvertent positive end expiratory pressure (PEEP) at high flow rates ${ }^{7}$ or the fast ventilator rates which are frequently triggered by very immature infants. ${ }^{8}$ Thus it seems likely that this ventilator could be used with success in a more varied group of infants. Our aim, therefore, was to use the Draeger ventilator to redefine the optimal role of PTV.

\section{Methods}

Infants were entered into the study when they had been stable on conventional ventilation for at least two hours and when a ventilator became available. All infants had previously been ventilated using Sechrist ventilators and had blood gases within the clinically acceptable range $(\mathrm{pH}$ $7 \cdot 25-7 \cdot 4$, arterial oxygen tension $\left(\mathrm{PaO}_{2}\right) 5 \cdot 33$ $9.33 \mathrm{kPa}$, arterial carbon dioxide tension $\left(\mathrm{PaCO}_{2}\right)$ 4.67-6.67 kPa).

The patients were then changed over to the Draeger Babylog 8000 ventilator and ventilated conventionally for one hour at the same settings as were previously in use. The ventilator was then switched into patient triggered mode for at least one hour. The Draeger Babylog 8000 utilises an airflow triggering system, a hot wire anemometer, which has the advantage of not increasing the dead space of the patient circuit. We have demonstrated that the median trigger delay of this system is between 80 and $100 \mathrm{~ms}$ at inflation times between 0.24 and 0.4 seconds. $^{6}$ On switching into the patient triggered mode the peak inspiratory pressure, PEEP, gas flow rate, and inspired oxygen concentration were not changed. An inflation time initially of 0.4 seconds was used, reducing in steps of 0.02 seconds, if necessary, until the spontaneous respiratory effort was no longer visibly distinct from the positive pressure inflation.

Throughout the study infants were monitored continuously using a Searle intra-arterial electrode or transcutaneous oxygen electrode. Infants were withdrawn from the study if, during PTV, their continuous monitoring demonstrated that the $\mathrm{PaO}_{2}$ was below $5.33 \mathrm{kPa}$. Arterial blood gas samples were obtained from the indwelling arterial line one hour after changing to the Draeger ventilator used conventionally and then again after one hour of trigger ventilation.

\section{ANALYSIS}

Differences in $\mathrm{PaCO}_{2}$ and $\mathrm{PaO}_{2}$ between study periods were assessed for significance using a paired Wilcoxon rank sum test. The change in $\mathrm{PaO}_{2}$ and $\mathrm{PaCO}_{2}$ over the first hour of PTV was expressed as a percentage of the values obtained immediately before PTV; these were then related to the infant's gestational and postnatal age and the severity of the infant's respiratory 
disease. Relationships were assessed for significance using a Wilcoxon rank sum test or Fisher's exact test.

\section{Patients}

Thirty three infants, all less than 35 weeks' gestational age, were recruited into the study. Their median (range) birth weight was 1508 (592-2700) $\mathrm{g}$ and gestational age 30 (24-34) weeks; they were studied at a median (range) postnatal age of $2 \cdot 5(0.25-50)$ days. The infants were all ventilated because of respiratory distress associated with prematurity. Immediately before the study their median (range) ventilator rate was 25 (4-90) breath/minute, peak (range) inspiratory pressure $17(12-25) \mathrm{cmH}_{2} \mathrm{O}$ and inspired oxygen concentration $35(21-80) \%$.

Ethical permission for this study was granted by the King's College Hospital ethics committee.

\section{Results}

No infant had to be withdrawn from the study because of low oxygen concentrations demonstrated by continuous monitoring. On analysis of the arterial blood gas concentrations at one hour, however, one infant ( 26 weeks' gestation)
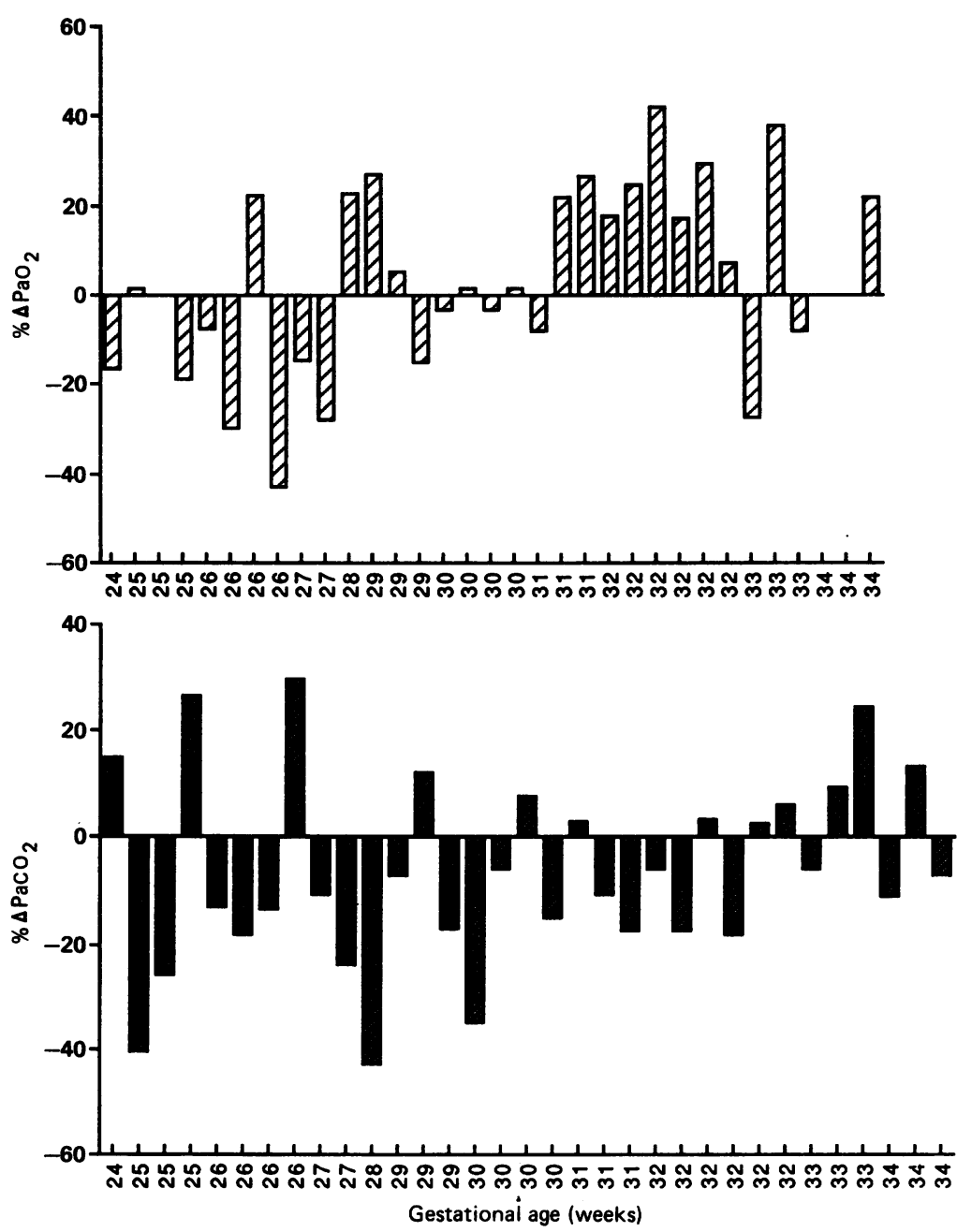

Figure 1 Percentage change in $\mathrm{PaO}_{2}$ and $\mathrm{PaCO}_{2}$ during $\mathrm{PTV}$ related to gestational age. Individual patient data is demonstrated by separate bars. had a $\mathrm{PaO}_{2}$ of $4.80 \mathrm{kPa}$, athough her continuous monitoring had suggested her oxygenation to be at the higher level of $5.33 \mathrm{kPa}$.

No significant change was found in $\mathrm{PaO}_{2}$ when blood gases were compared between the period of conventional ventilation and PTV: $\mathrm{PaO}_{2}$ increased in 17 patients, decreased in 13 and there was no change in the remaining three infants (fig 1). Oxygenation significantly improved in infants greater than 28 weeks' gestational age $(\mathrm{p}<0.05)$, with a median (range) improvement in $\mathrm{PaO}_{2}$ of $7(-28$ to +42$) \%$. Fifteen of the 23 infants of gestational age greater than 28 weeks had an improvement in oxygenation, compared with only two of the 10 infants less than 28 weeks gestational age $(p<0.05)$. Oxygenation also significantly improved in the subgroup of infants of greater than 28 weeks' gestation who were ventilated at a rate of more than 15 breaths/minute $(p<0.05)$. There were no significant relationships between changes in oxygenation and postnatal age, fractional inspired oxygen concentration $\left(\mathrm{FIO}_{2}\right)$ or peak inspiratory pressure (table 1 ).

$\mathrm{PaCO}_{2}$ showed a significant decrease over the PTV study period, decreasing in 21 patients and increasing in 12 patients, median (range) change $-7(-43$ to +29.4$) \%(p<0.05)$. This change in $\mathrm{PaCO}_{2}$ was neither significantly related to gestational nor postnatal age (fig 1). In the 12 patients whose $\mathrm{PaCO}_{2}$ increased, the median ventilator rate on conventional ventilation was significantly higher than in the 21 patients in whom $\mathrm{PaCO}_{2}$ decreased $(\mathrm{p}<0.05)$ (fig 2, table 2). No significant relationships were found between changes in $\mathrm{PaCO}_{2}$ and either the peak inspiratory pressure or improved oxygen concentration $\left(\mathrm{FIO}_{2}\right)$ (table 2 ).

The improvement in oxygenation was associated with a reduction in $\mathrm{PaCO}_{2}$ in 12 patients, but a rise in $\mathrm{PaCO}_{2}$ in five others. These five infants had been previously ventilated at a significantly higher rate than the rest of the study group $(p<0.05)$. A deterioration in $\mathrm{PaO}_{2}$ was accompanied by a fall in $\mathrm{PaCO}_{2}$ in nine patients (these infants were significantly less mature, but older than the rest of the study group; $p<0.05$ ) and a rise in $\mathrm{PaCO}_{2}$ in seven others. Infants in whom there was no improvement in either $\mathrm{PaO}_{2}$ or $\mathrm{PaCO}_{2}$ required a higher inspired oxygen concentration $(p=0.054)$ and peak inflating pressure than the remaining infants (table 3 ). Infants whose blood gases improved on PTV were maintained on this mode for up to several days or until extubation; no complications were experienced.

Table 1 Changes in oxygenation. Results are median (range)

\begin{tabular}{|c|c|c|}
\hline & $\begin{array}{l}\text { Increase } \\
\text { in } \mathrm{PaO}_{2}\end{array}$ & $\begin{array}{l}\text { No change } \\
\text { or decrease } \\
\text { in } \mathrm{PaO}_{2}\end{array}$ \\
\hline $\begin{array}{l}\text { No of infants } \\
\text { Ventilator rate during conventional } \\
\text { ventilation (breaths/min) } \\
\mathrm{FIO}_{2}(\%)\end{array}$ & $\begin{array}{l}17 \\
30 \\
(7-90) \\
30\end{array}$ & $\begin{array}{l}16 \\
24 \\
(4-78)\end{array}$ \\
\hline $\begin{array}{l}\text { Peak inspiratory pressure } \\
\left(\mathrm{cmH}_{2} \mathrm{O}\right) \\
\text { Postnatal age (days) }\end{array}$ & $\begin{array}{l}17 \\
(12-22) \\
2 \\
(0 \cdot 25-46)\end{array}$ & $\begin{array}{l}(21-00) \\
15 \\
(12-25) \\
2 \cdot 5 \\
(0 \cdot 25-50)\end{array}$ \\
\hline
\end{tabular}




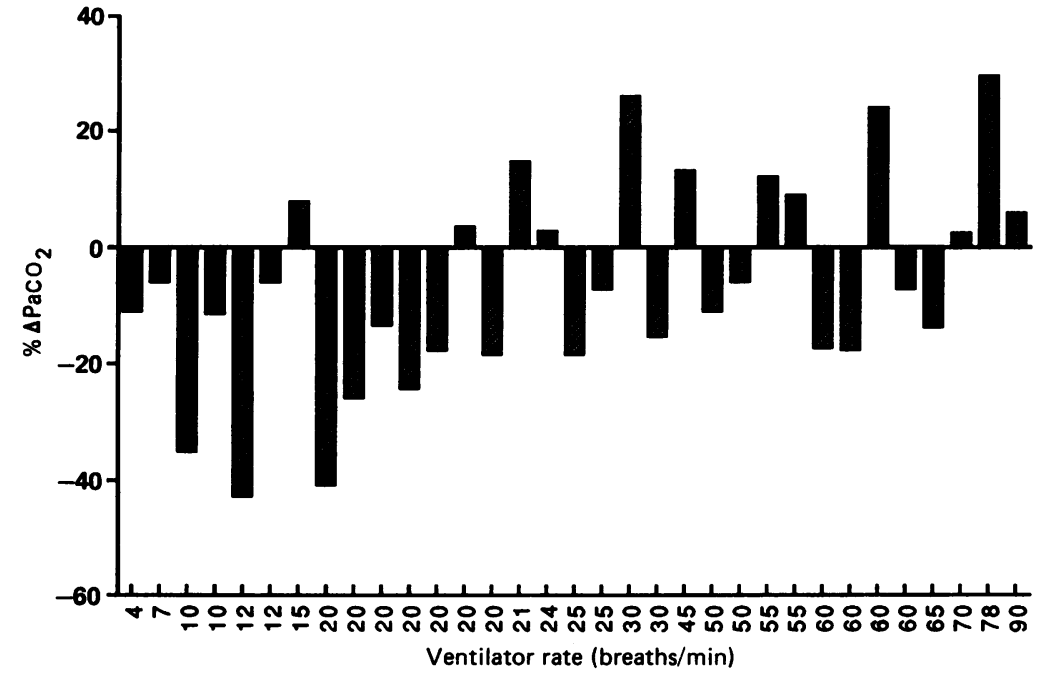

Figure 2 Percentage change in $\mathrm{PaCO}_{2}$ related to ventilator rate during conventional ventilation. when compared with similar pressure settings on conventional ventilation. ${ }^{9}$ This improvement in alveolar ventilation on PTV compared with conventional ventilation is particularly likely with the short inflation times ${ }^{9}$ used in this study for infants of all gestational ages. Thus, it is not unexpected that changes in $\mathrm{PaCO}_{2}$ were not related to the maturity of the infant. Oxygenation, however, is determined by mean airway pressure (MAP). ${ }^{10}$ Inflation time during PTV was always shorter than conventional ventilation, particularly in the smallest infants; this would reduce MAP and hence oxygenation.

The only significant relationship of change in $\mathrm{PaCO}_{2}$ was with the ventilator rate previously used on conventional ventilation. At low rates during conventional ventilation only a small proportion of spontaneous breaths can be supported by a positive pressure inflation. In contrast, during PTV, all spontaneous breaths may trigger the ventilator, resulting in both an increase in tidal and minute volume. Thus $\mathrm{PaCO}_{2}$ will be affected to a greater extent by changing to PTV from conventional ventilation at a low ventilator rate than a high one. The greater reduction in $\mathrm{PaCO}_{2}$ at lower ventilator rates suggests PTV may have a useful role in weaning when infants are recovering from respiratory distress syndrome and are usually supported on intermittent mandatory ventilation.

We have previously demonstrated that failure of oxygenation to improve after one hour is an accurate predictor of a lack of successful respiratory support by PTV. ${ }^{4}$ The results of this study, therefore, indicate that despite improvements in ventilator design and performance there remains a substantial proportion of infants for whom PTV is not a useful alternative to conventional ventilation. The failure to improve oxygenation in the most immature infants, the greater reduction in $\mathrm{PaCO}_{2}$ at previously low ventilator rates and the combination of failure of oxygenation and increase in $\mathrm{PaCO}_{2}$ in infants at the highest inspired oxygen concentration all suggest PTV is more suitable for infants with mild, not severe, respiratory distress.

Dr M Hird is supported by Children Nationwide Medical Research Fund. We thank Ms Sue Williams for secretarial assistance.

\section{Discussion}

Initial inspection of the results might suggest that PTV appeared to confer no advantage in improving oxygention over conventional ventilation, as there was no significant improvement in the study population overall. Oxygenation, however, improved in infants of gestational age of more than 28 weeks, with a similar improvement in the subset of that group ventilated at rates of more than 15 breaths/minute. There was a deterioration in oxygenation in the group of infants of gestational age 28 weeks or less, which confirms our preliminary findings in five other immature infants. ${ }^{6}$ Thus, despite using a superior ventilator design and performance, ${ }^{6}$ PTV is still unsuitable for infants of extreme prematurity.

In contrast, changes in $\mathrm{PaCO}_{2}$ were not significantly related to gestational age. During PTV, tidal volume and minute volume are increased

\footnotetext{
1 Mehta A, Callan K, Wright BM, Stacey TE. Patient triggered ventilation in the newborn. Lancet 1986;ii:17-9.

2 Greenough A, Greenall F. Patient triggered ventilation in premature neonates. Arch Dis Child 1988;63:77-8.

3 Greenough A, Pool J. Neonatal patient triggered ventilation. Arch Dis Child 1988;63:394-7.

4 Mitchell A, Greenough A, Hird MF.Limitations of neonatal patient triggered ventilation. Arch Dis Child 1989;64: patien 9 .

5 Hird MF, Greenough A. Causes of failure of neonatal patient triggered ventilation. Early Hum Dev 1990;23:101-8.

6 Hird MF, Greenough A. Gestational age: an important influence on the success of patient triggered ventilation. influence on the success of patient trigge
Clin Phys Physiol Meas 1990;11:307-12.

7 Greenough A, Greenall F. Performance of respirators at fast rates commonly used in neonatal intensive care unit. rates commonly used in neona

8 Greenough A, Greenall F, Gamsu H. Synchronous respiration-which ventilator rate is best? Acta Paediat Scand 1987:76:713-8.

9 Upton CJ, Milner AD, Stokes GM. The effect of changes in inspiratory time on neonatal triggered ventilation. Eur f Pediatr 1990;149:648-50.

10 Boros SJ. Variation in inspiratory:expiratory ratio and airway pressure waveform during mechanical ventilation: the significance of mean airway pressure. $f$ Pediatr 1979;94: $114-7$.
} 